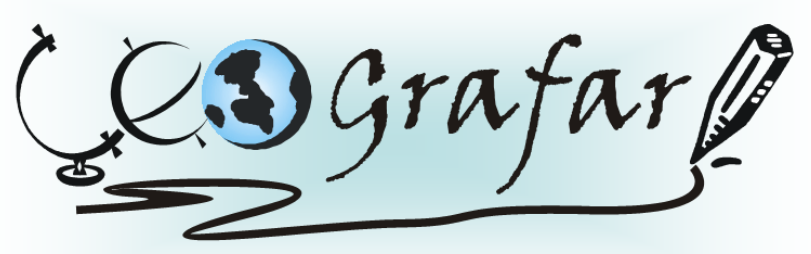

Revista Eletrônica do Programa de Pós-Graduação em Geografia - UFPR

\title{
IDENTIFICAÇÃO DE ÁREAS DE PRESERVAÇÃO PERMANENTE E DE CONFLITOS POTENCIAIS DE USO NO SETOR CENTRO-LESTE DO PLANALTO DE FRANCISCO BELTRÃO - SW/PR
}

\section{IDENTIFICATION OF AREAS FOR PERMANENT PRESERVATION AND POTENTIAL CONFLICTS OF USE SECTOR IN CENTRAL EASTERN HIGHLANDS OF BELTRÃO FRANCISCO - SW / PR}

(Recebido em 07.02.2013; Aceito em: 10.06.2013)

Benice Folador

Professora da Faculdade Mater Dei

Pato Branco, PR, Brasil

e-mail: befolador@hotmail.com

\section{RESUMO}

A pesquisa apresenta as Áreas de Preservação Permanente - APP e de conflitos potenciais de uso do solo no setor centro-leste do Planalto de Francisco Beltrão, Sudoeste do Paraná. A análise foi efetuada a partir do reconhecimento das características físicas de relevo e hidrografia, bem como do uso do solo existente na área, utilizando-se de técnicas do Geoprocessamento e Sensoriamento Remoto. As APP foram individualizadas de acordo com a legislação ambiental brasileira. A área estudada apresenta $139.061,81$ ha, dos quais $26.515,60$ ha são consideradas áreas sensíveis ao meio ambiente. De acordo com as categorias de APP, $19 \%$ da área de estudo são protegidas pela legislação. Dos tipos de APP existentes na área estudada, a preservação ao longo dos cursos d'água responde pela maior extensão das áreas protegidas $(15.218,93 \mathrm{ha})$. As menores participações entre as APP correspondem às encostas com declividade superior a $45^{\circ}$ (2.190,23ha), e as APP de categoria Morro (1.155,59 ha). Identificou-se cinco classes de uso do solo no setor centro leste do Planalto de Francisco Beltrão: lavoura colhida, representando 9,20\%; floresta, com 25,43\%; área urbana 3,05\%; lavoura em desenvolvimento $31,89 \%$ e solo exposto $30,43 \%$. As áreas de conflito de uso concentram-se ao longo da margem do rio Chopim, bem como de seus afluentes nas proximidades da confluência. As áreas de conflito relacionadas aos canais constituem grande 
número, distribuídas aleatoriamente em toda a área de estudo. As APP ocupadas com florestas foram consideradas uso adequado do solo e perfazem total de 13.103,70ha. Das áreas indicadas pelas variáveis relevo e hidrografia em que as APP foram ocupadas, seja com lavoura em desenvolvimento, lavoura colhida, área urbana ou solo exposto, foram consideradas uso inadequado do solo. Essas representam área de $12.128,50$ ha no setor centro-leste do Planalto de Francisco Beltrão.

Palavras Chaves: Áreas de Preservação Permanente; Conflitos de Uso; Legislação Ambiental.

\section{ABSTRACT}

The survey shows permanent preservation areas and use of potential conflicts in the sector East-Central Plateau of Francisco Beltrão, Southwest of Paraná. The analysis was performed based on the recognition of the physical topography and hydrography characteristics as well as the existing land use in the area using geoprocessing techniques. The sectors of APP were individualized according to the Brazilian Forest Code in force. The study area presents 139,061.81 ha, which 26,515.60 ha are considered environmentally sensitive areas. In accordance with the APP categories analyzed APP (relief elevations, slope above $30^{\circ}$, hydrography), and what the Forest Code defines as APP, 19\% of the area study are protected by law. Types of APP in the area studied, the preservation along the waterways accounts for the largest size of protected areas $(15,218.93 \mathrm{ha})$. The lowest shares among the APP corresponding to the slopes greater than $45^{\circ}(2,190.23 \mathrm{ha})$, and APP category Morro (1,155.59 ha). It was identified five classes of land use in central-eastern sector of the Plateau Francisco Beltrão: crops harvested representing 9.20\%; forest, with $25.43 \%$, urban area $3.05 \%$, crop developing the total $31.89 \%$ and $30.43 \%$ exposed soil. The conflict areas of use are concentrated along the river bank Chopim and its tributaries near the confluence. The areas of conflict related to the springs channels are distributed randomly across the study area. The APP occupied by forests was considered appropriate use of land and add up to total of 13,103.70 ha. Those areas that were indicated by variables such as topography and hydrography of APP and that the land use analysis showed occupation either with the developing crop, harvested crops, bare soil or urban area, were considered inappropriate land use. These represent the area of $12,128.50$ ha in east-central sector of the Plateau Francisco Beltrão.

Keywords: Areas of Permanent Preservation; Conflicts of Use; Environmental Legislation.

\section{INTRODUÇÃO}

Os impactos produzidos ao meio ambiente causados pelo uso intensivo da agricultura, mudanças de uso do solo, diferentes sistemas de produção, ocupações 
irregulares e novos empreendimentos nos diversos setores da sociedade, causam destruição e alteração ambiental. No setor agrícola os impactos podem ser agrupados em dois grandes conjuntos de ações: o uso de agrotóxicos e o desmatamento, e consequentemente a erosão do solo. Este último desencadeado tanto pela intensa mecanização, quanto pelo uso de áreas inadequadas ao plantio, como margens de rios e áreas com declives acentuados.

Em relação à produção agrícola o estado do Paraná é considerado, a nível nacional, o maior produtor de grãos do país, como milho, soja, trigo e feijão. E a região Sudoeste do Paraná, composta pelos núcleos regionais de Francisco Beltrão e Pato Branco, corresponde à terceira região mais importante do estado, com produções de soja, milho, feijão e trigo, as quais são as principais alternativas para o agricultor, conforme dados estatísticos do Instituto Paranaense de Desenvolvimento Econômico Social - IPARDES (2009), portanto torna-se necessário avaliar se, apesar da intensa prática agrícola, as características ambientais estão sendo respeitadas.

Por esta situação, é importante um estudo, baseado na legislação ambiental, que viabilize indicadores ambientais georreferenciados, que possam auxiliar os gestores públicos e proprietários rurais, considerando a questão da preservação ambiental e o uso do solo versus a economia da região.

O presente estudo, busca contribuir aos municípios no sentido de uma participação ativa junto ao Sistema de Manutenção, Recuperação e Proteção da Reserva Florestal Legal - SISLEG, por estar intimamente relacionado às Áreas de Preservação Permanente - APP. Também, importante como base para projetos de implantação de unidades de conservação e respectivos planos de manejo. E principalmente, por meio da ocupação e uso do solo da área de estudo, identificar regiões que estão em conflito com áreas de preservação ambiental.

Sendo assim, os objetivos da pesquisa podem ser resumidos em identificar APP no setor centro-leste do Planalto de Francisco Beltrão, conforme legislação ambiental, e relacionar com o uso do solo, indicando os setores de conflitos potenciais de uso. Para tal, por meio das técnicas de Geoprocessamento, a partir de 
imagens de satélites, são identificadas e delimitadas as APP, após, a geração de Mapa das APP, considerando o percentual de cobertura em toda área de estudo e reconhecimento dos diferentes tipos de usos do solo. Por fim, relacionar as APP identificadas com o uso de solo existente, verificando possíveis áreas de conflito entre APP e uso do solo, avaliando que categorias de preservação são espontaneamente obedecidas pelos produtores rurais, bem como apontar o conflito decorrente do uso de tais terras.

A área de estudo compreende o setor drenado pelos rios Pato Branco, Pinheiro e Vitorino, afluentes da margem esquerda do rio Chopim. Está localizada na Região Sudoeste do Estado do Paraná, especificamente no setor Centro Leste do Planalto de Francisco Beltrão, entre as coordenadas geográficas de $26^{\circ}$ e $27^{\circ}$ de latitude Sul e $53^{\circ}$ e 52 de longitude Oeste.

Em termos administrativos, corresponde quase à totalidade aos municípios de Pato Branco, Mariópolis, Vitorino e Itapejara do Oeste. Abrange, ainda, pequenas porções territoriais dos municípios de Bom Sucesso do Sul, Clevelândia, Honório Serpa, Coronel vivida, Chopinzinho, Verê, São João, Renascença e Francisco Beltrão (Figura 1). Totaliza uma área de 1391, $02 \mathrm{Km}^{2}$, perfazendo um perímetro de $216.715,72 \mathrm{Km}$, com $400 \mathrm{~km}$ de extensão N-S e $380 \mathrm{~km}$ de extensão LE.

Os dados geológicos (Formação Serra Geral) é composto por rochas vulcânicas e de natureza química-mineralógica, com ocorrências de litotipos de riolitos e riodacitos. (NARDY et al., 2002; VOLKMER e RIBEIRO, 2004; VOLKMER e FORTES, 2003; SCHNEIDER et al., 1974; MAACK, 1981; FODOR et al., 1989; NARDY et al., 1993).

A área de estudo está inserida no Planalto de Francisco Beltrão, correspondendo mais especificamente ao setor Centro Leste, com altitudes variando entre $480 \mathrm{~m}$ a $1080 \mathrm{~m}$; ocorrendo várias formas de relevo (PAISANI et. al., 2008b) como topos relativamente planos (acima de $800 \mathrm{~m}$ ), constituindo o divisor d'águas regional entre a Bacia do Rio Uruguai, ao sul, e a Bacia do Iguaçu, ao norte. A partir desse divisor para o interior da área estudada, individualizam-se plataformas, entre 600 e $800 \mathrm{~m}$ de altitude. Entre os patamares, divisores locais da drenagem que deságua no Iguaçu, aparecem vales, geralmente, com formato de $\mathrm{V}$, podendo se mostrar mais abertos e com encostas, na sua maioria, convexas. Os vales mais 
abertos, em geral apresentam formas embutidas como ombreiras de fundo de vale, aparecendo em cotas abaixo de $600 \mathrm{~m}$ (PAISANI et al., 2008b).

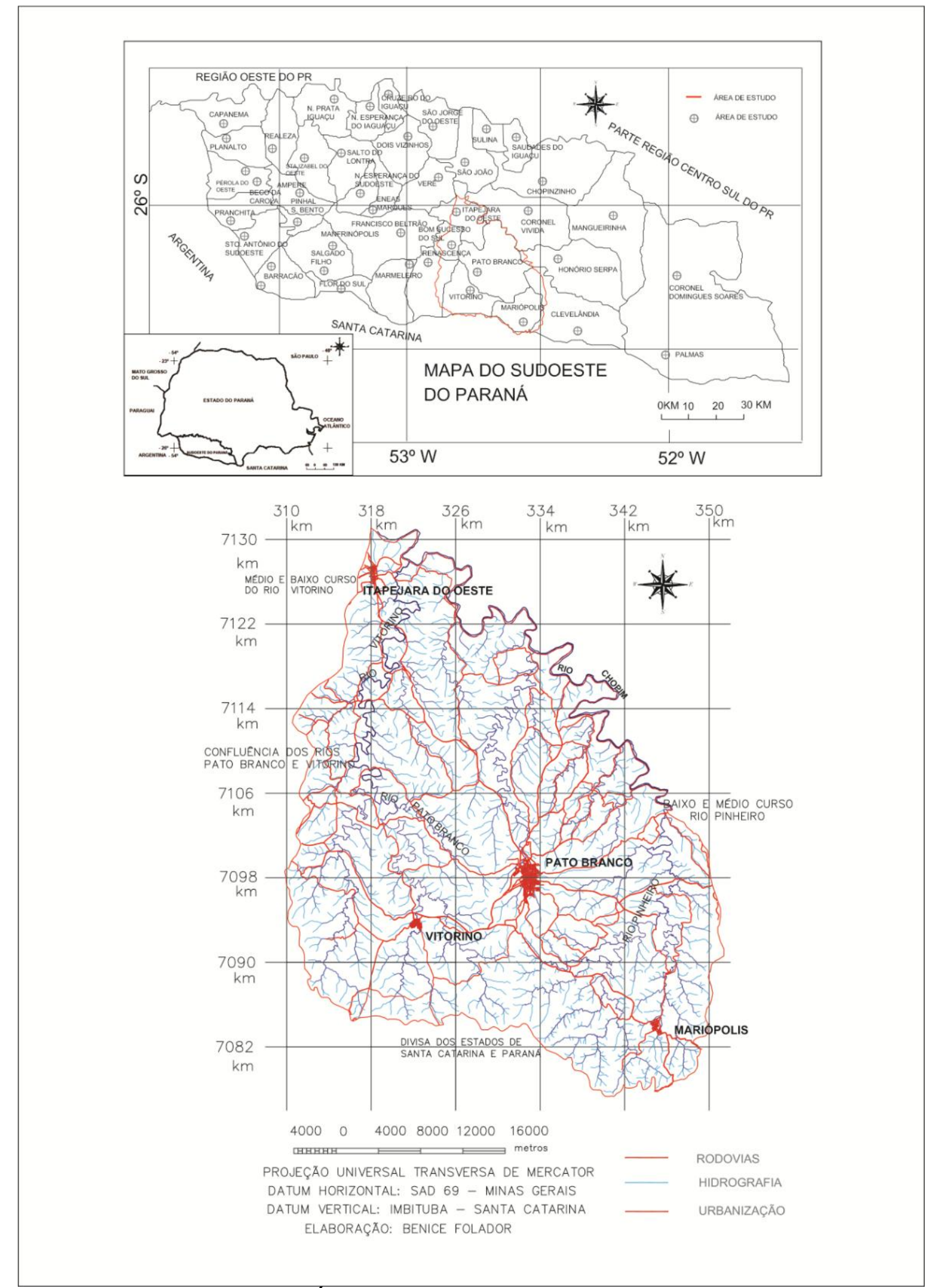

Figura 1 - Localização da Área de Estudo - Setor Centro Leste do Planalto de Francisco. 
Grande parte da área de estudo é ocupada pelos solos tipo Latossolos Vermelhos distroférrico. Nas cabeceiras do Rio Vitorino aparecem manchas de Latossolo Bruno Distrófico e de Nitossolo Vermelho distrófico (BHERING e SANTOS, 2008).

Ao longo de praticamente todo o fundo de vale dos rios Pinheiro e Vitorino e margens do rio Chopim ocorrem solos da classe dos Neossolos Regolítioco. São solos pedregosos, com textura argilosa, associados a setores de relevo forte ondulado (BHERING e SANTOS, 2008).

As características de clima (zona climática subtropical mesotérmica úmida, Cfb na classificação de Köeppen) da região, associado ao tipo de cobertura pedológica predominante, favorecem o desenvolvimento de vegetação tipo floresta (Floresta Subcaducifólia Subtropical).

\section{MATERIAL E MÉTODOS}

Para a identificação e delimitação das APP do setor Centro- Leste do Planalto de Francisco Beltrão, considerando os aspectos físicos de relevo e hidrografia da área estudada, segue-se os parâmetros determinados pelo Código Florestal Brasileiro - CFB vigente e Resoluções específicas do Conselho Nacional do Meio Ambiente - CONAMA (ANTUNES, 2008; RESOLUÇÃO CONAMA № 303, 2002, p. 2: RESOLUÇÃO CONAMA № 04, 1985).

Conforme Código Florestal Brasileiro (incluído pela Medida Provisória no 2.166-67, de 2001, p.1), considerando a hidrografia, são APP, florestas e demais formas de vegetação natural, situadas ao longo dos cursos d'água e nascentes, em diferentes larguras de faixas marginais.

Em relação ao relevo, são consideradas APP os topos de morros e encostas com declive superior a $45^{\circ}$ equivalente a $100 \%$ na linha de maior declive (Código Florestal Brasileiro, Lei $n^{\circ}$ 4.771, de 15-09-1965).

Além das APP, para o CFB, art. $10^{\circ}$, "não é permitida a derrubada de florestas, situadas em áreas de inclinação entre $25^{\circ}$ a $45^{\circ}$ " (Código Florestal

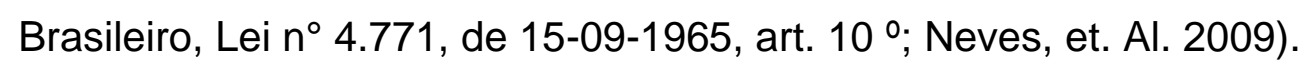

A análise do relevo, hidrografia e uso do solo do setor Centro Leste do Planalto de Francisco Beltrão foi obtida a partir do manuseio de documentos 
cartográficos, imagens de satélite e softwares de Geoprocessamento como Autodesk LAND Development Suit, AutoCAD Map e SPRING - Sistema de Processamento de Informação Geográfica (SIG).

Para tanto foram utilizados folhas topográficas e imageamento orbital SPOT5 (Satellite Probatoire d'Observation de la Terre) dos seguintes municípios: Verê (MI - 2850/3); Coronel Vivida(MI - 2850/4); Mato Branco (MI - 2851/3); Renascença (MI - 2862/1); Pato Branco (MI - 2862/2); Esti (MI - 2863-1); São Lourenço do Oeste (MI - 2862/3); Mariópolis (MI- 2862/4); Clevelândia (MI - 2869/3) do Exército e Diretoria de Serviço Geográfico, e, Secretaria de Estado do Desenvolvimento Urbano - SEDU; escala 1:50.000; equidistância entre as curvas de nível: 20 m; Projeção Universal Transversa de Mercator; Datum Vertical: Imbituba - Santa Catarina; Datum Horizontal - SAD 69 - Minas Gerais.

As etapas de produção se deram na seguinte ordem: Elaboração da Base Cartográfica de Apoio composta de rede hidrográfica, sistema viário, manchas urbanas, curvas de nível e pontos cotados, planos de informações que possibilitaram gerar as cartas de hipsometria e declividade; Delimitação da Área de estudo; Geração dos Mapas Temáticos de hipsometria e declividade; Identificação das APP, georreferenciadas e relacionadas à hidrografia e relevo; e, Classificação das Imagens e Geração do Mapa de Uso e Ocupação do Solo.

\subsection{Obtenção das APP nos Cursos d'Água, Declividade e Relevo}

A partir da rede hidrográfica, as larguras dos canais e cabeceiras de drenagem foram dimensionadas, e após, delimitadas a margem de proteção da mata ciliar.

Por meio do Mapa de Declividade, que representa a declividade do relevo, em graus, foi determinado intervalos entre $20^{\circ}$ e $45^{\circ}$ que caracterizam relevo fortemente ondulado, e acima de $45^{\circ}$, equivalente a $100 \%$ de inclinação na linha de maior declive, um relevo montanhoso (EMBRAPA, 1999).

O CFB considera as regiões de declividade superior ou igual a $45^{\circ}$ Áreas de Preservação Permanente. Já para os ambientalistas, declividades iguais e superiores a $30^{\circ}$ já são áreas consideradas sensíveis e devem ser protegidas, 
garantindo a proteção dos solos e recursos hídricos (METZGER, 2010; MENDONÇA, 1999; AB'SABER, 2010).

Para identificar as APP relacionadas à declividade da área de estudo, cada intervalo de classe de declividade foi separado por camada (layers). Somente as camadas correspondentes aos setores com $45^{\circ}$ de inclinação foram selecionadas e designadas como APP.

Também foi possível a identificação e delimitação das APP por meio das curvas de nível e dos pontos cotados, os quais possibilitaram representar as elevações de terrenos com cotas de topo, em relação à base, entre 50 a 300m, considerando o declive maior que $30 \%$, ou seja, 13․ Toda área drenada foi analisada em função da declividade e curvas de nível.

\subsection{Classificação das Imagens e Geração do Mapa de Uso e Ocupação do Solo e Cruzamento das Informações}

Para a caracterização dos diferentes tipos de uso do solo e geração do mapa temático foram importadas as imagens orbitais no aplicativo SPRING e criado um banco de dados com Plano de Informação para cada imagem que recobre a área de estudo.

De forma supervisionada, obteve-se as amostragens para cada classe de uso do solo, sendo solo exposto, lavoura em desenvolvimento, área urbana, floresta, lavoura colhida e hidrografia. A escolha das classes foi consonante com a resolução espacial das imagens, sendo que área urbana foi separada espectralmente por polígono, visando minimizar o grau de confusão de assinatura de cada pixel em cada classe.

Para proceder-se à análise de uso e ocupação do solo nas áreas de preservação permanente, obtendo informações de coberturas de áreas e percentuais de ocupação, cruzou-se os dados de uso do solo e APP. Novas reclassificações foram realizadas em função das classificações já efetuadas. 


\section{RESULTADOS}

A partir do cruzamento dos mapas de APP geral e de uso do solo foi possível identificar as áreas de conflito de uso que ocorrem no setor centro-leste do Planalto de Francisco Beltrão.

\subsection{Os aspectos da hipsometria e APP elevações do relevo}

As altitudes do relevo na área situam-se entre 480 e 1080m (Figura 2). $O$ CFB considera APP setores do relevo com altitudes iguais ou superiores a $1800 \mathrm{~m} o$ que não é o caso da área estudada. No entanto, a análise é importante à noção geral da elevação do terreno para a área de estudo.

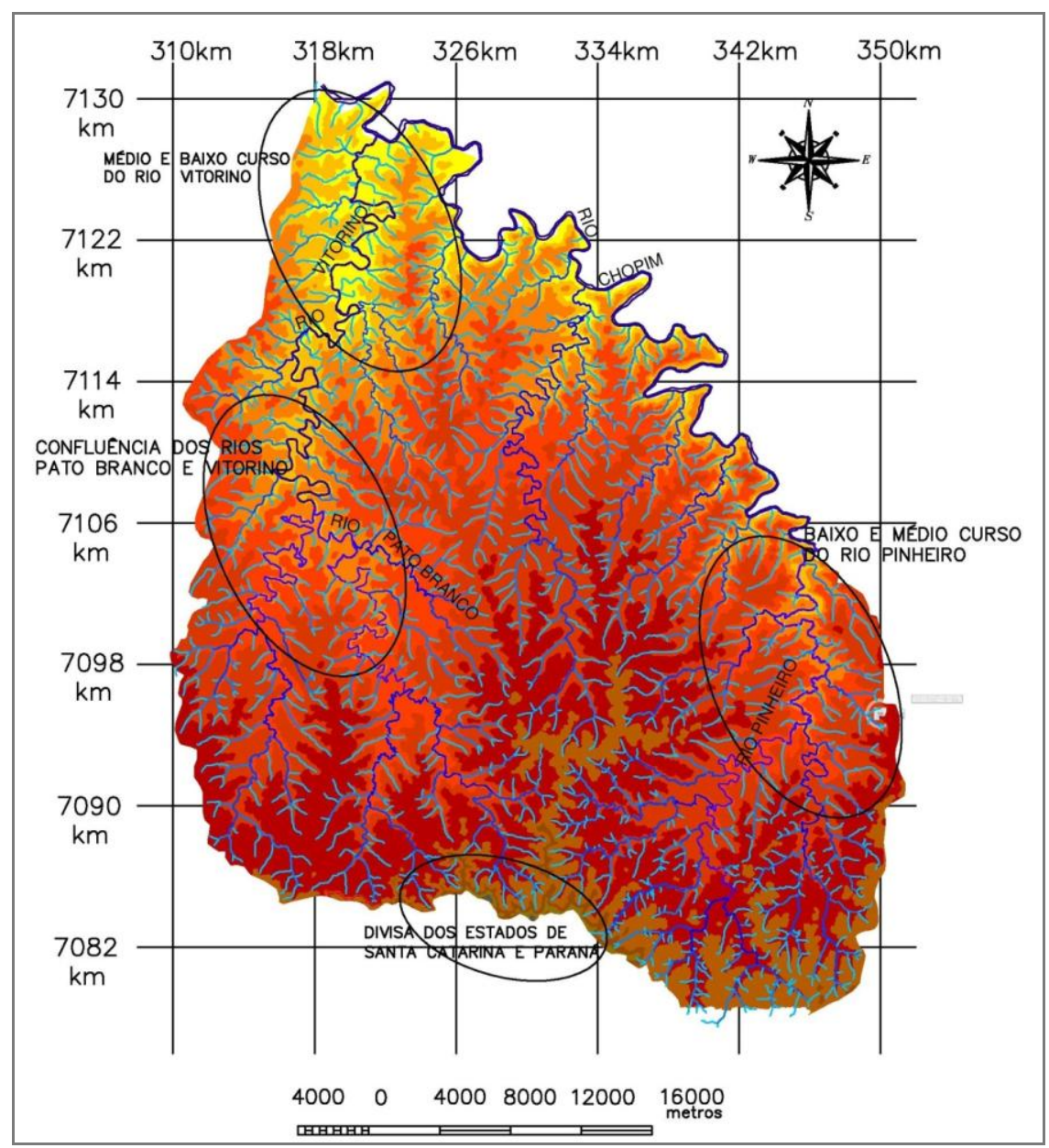

Figura 2 - Hipsometria do setor Centro Leste do Planalto de Francisco Beltrão. 
Destaca-se, de modo geral, quatro agrupamentos de intervalos predominantes: 480 e 660 metros com uma cobertura de $37 \%$ da área de estudo, caracterizando fundo de vales, na margem do rio chopim e afluentes e sub-bacia do rio Vitorino; 661 e 780 metros com cobertura de 42,8\%, sendo divisores locais que individualizam as sub-bacias existentes na área, principalmente nas Sub-bacias dos rios Ligeiro e Vitorino, e margens do rio Chopim; 781 a 860 metros com cobertura de $20 \%$, compondo o patamar central, localizado no centro e faixa centro-sul da área de estudo. Acima de 981 metros há somente $0,2 \%$ de cobertura nas cabeceiras dos rios que formam as bacias dos rios Vitorino, Pato Branco e Pinheiro, no divisor dos Estados de Santa Catarina e Paraná.

A partir da distribuição das curvas de nível, ainda é possível identificar setores de APP relacionadas ao relevo (Figura 3), como pequenos morros isolados (representado em cor verde sobre imageamento SPOT -5), principalmente do divisor de águas entre os afluentes do baixo curso do rio Vitorino e canais que drenam diretamente ao rio Chopim.

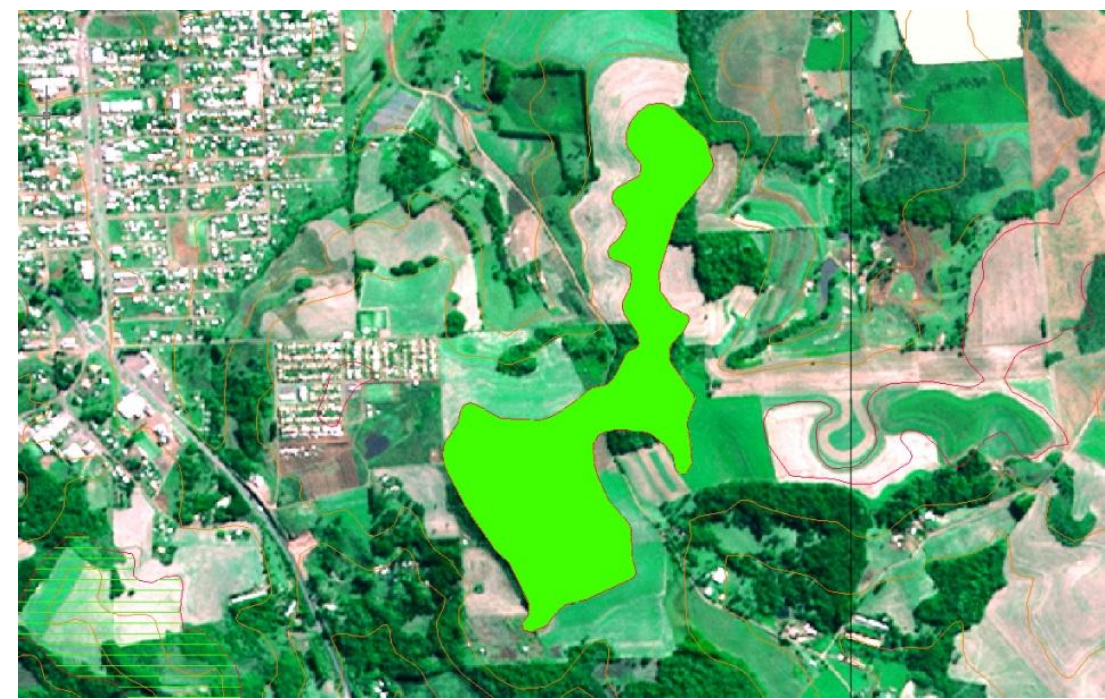

Figura 3 - APP de elevação do relevo no Setor Centro Leste do Planalto de Francisco Beltrão - PR.

\subsection{Os aspectos da declividade e APP}

Aproximadamente $80 \%$ do total da área apresenta declividades entre $0^{\circ} \mathrm{e}$ 20ำ (Figura 4), o que indica segundo critérios da EMBRAPA (apud Nogueira, 2008) predomínio de relevo com morfologia plana à ondulada (Quadro 1). 


\begin{tabular}{|c|c|c|}
\hline $\begin{array}{c}\text { Declividade } \\
\text { (graus) }\end{array}$ & Percentual de Cobertura & Tipo de Relevo \\
\hline $0-3$ & $34 \%$ & Plano \\
\hline $3-8$ & $2 \%$ & Suavemente Ondulado \\
\hline $8-20$ & $43 \%$ & Fortemente Ondulado \\
\hline $20-30$ & $13 \%$ & Fortemente Ondulado \\
\hline $30-45$ & $6 \%$ & Montanhoso \\
\hline$>45$ & $2 \%$ & \\
\hline
\end{tabular}

Quadro 1 - Classificação do Relevo da Área Estudada em Relação a Declividade Setor Centro Leste do Planalto de Francisco Beltrão.

Fonte: Adaptado de EMBRAPA, 1999. 


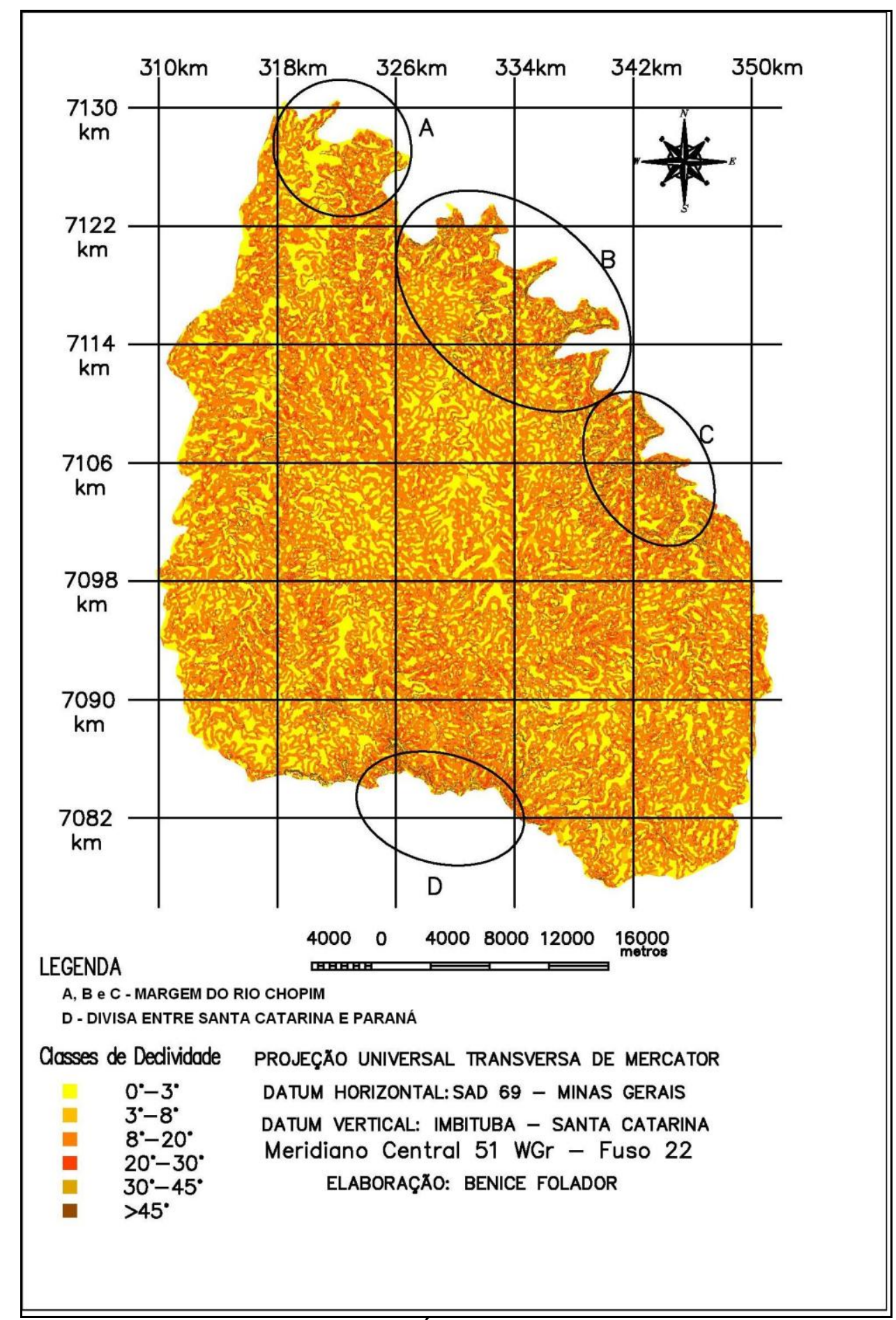

Figura 2 - Mapa de Declividade da Área de Estudo.

Em regiões com declividades superiores a 30ํㅡㄹ ou seja, de relevo fortemente ondulado, já devem ser aplicados os critérios de preservação. Se esta fosse a determinação do CFB, no setor centro-leste do Planalto de Francisco Beltrão, 19\% da área total, que correspondem ao intervalo de declividades entre $20^{\circ}$ e $45^{\circ}$, deveriam ser preservados (Quadro 1). Considerando a declividade estipulada como 


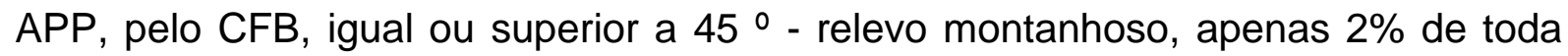
área de estudo são destinados à preservação. Isso equivale a 22.144,14ha, do total de 139.061,81 ha existente na área estudada (Quadro 1).

Predominam na área de estudo declividades até $30^{\circ}$, principalmente no centro da área, que corresponde a boa parte do município de Pato Branco (Figura 4). Verifica-se concentração de declividades maiores de $30^{\circ}$ praticamente ao longo de toda a margem do rio Chopim (Figura 4 - A, B e C) e no setor de divisor regional de águas entre os estados do Paraná e Santa Catarina (Figura $4-D$ ).

\subsection{Os aspectos hidrográficos e as APP}

Observa-se grande densidade de canais na área estudada (Figura $1 \mathrm{e}$ Figura 5), sendo apenas no entorno do perímetro urbano de Pato Branco, setor das cabeceiras do rio Ligeiro, onde se observa menor densidade. Os canais de $1^{\text {a }}$ ordem apresentam-se relativamente mais curtos nas áreas de cabeceiras das subbacias dos rios Vitorino, Pato Branco e Pinheiro (altitudes maiores de $781 \mathrm{~m}$ ). Para jusante observa-se extensão maior dos canais de $1^{\text {a }}$ ordem (Figura 5).

As APP relacionadas à hidrografia distribuem-se de modo uniforme por toda a área de estudo, constituindo densidade alta de manchas (Figura 5). Isso porque referem-se aos aspectos tanto dos setores das cabeceiras de drenagem, ligadas aos canais de $1^{\text {a }}$ ordem hierárquica, quanto das margens dos canais. Nesses últimos, quanto maior a largura dos canais de drenagem, tanto maior será a extensão de preservação nas margens.

\subsection{APP geral da área}

O mapa geral das APP apresenta as classes de preservações consideradas pela legislação, apresentadas em diferentes tonalidades de verde (Figura 6).

O setor Centro Leste do Planalto de Francisco Beltrão compreende área total de 139.061,81ha. Desse total, 26.515,60ha são consideradas áreas sensíveis ao meio ambiente. De acordo com as categorias de APP mencionadas, e com o que define o Código Florestal como APP, $20 \%$ da área de estudo são protegidas pela legislação (Quadro 2). 


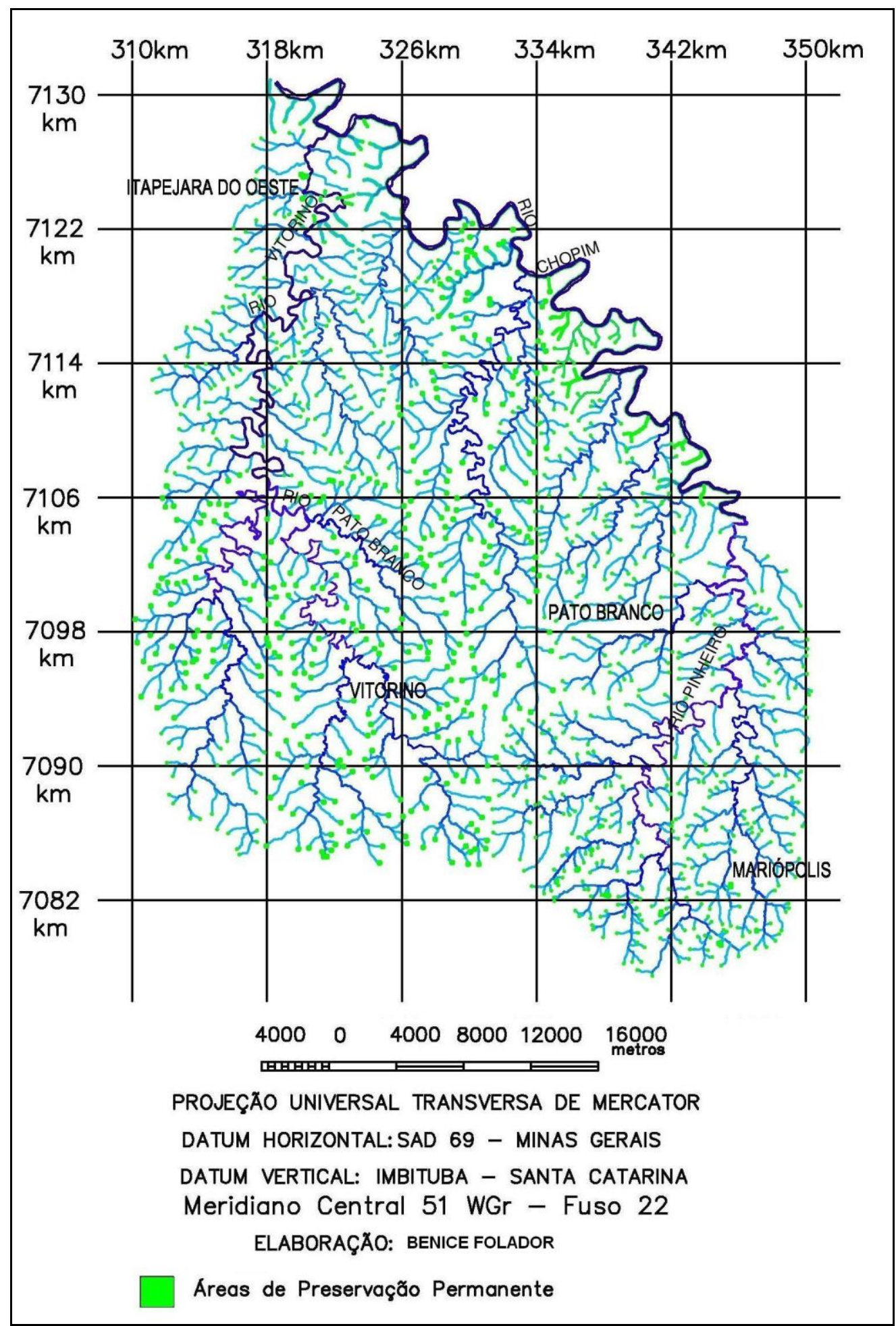

Figura 3 - Mapa das APP de Hidrografia do setor Centro Leste do Planalto de Francisco Beltrão - PR.

Dos tipos de APP existentes na área estudada, a preservação ao longo dos cursos d'água responde pela maior extensão das áreas protegidas (15.218,93ha). As menores participações entre as APP correspondem às encostas com declividade superior a 45ำ (2.190,23ha), e as APP de categoria Morro (1.155,59ha). 


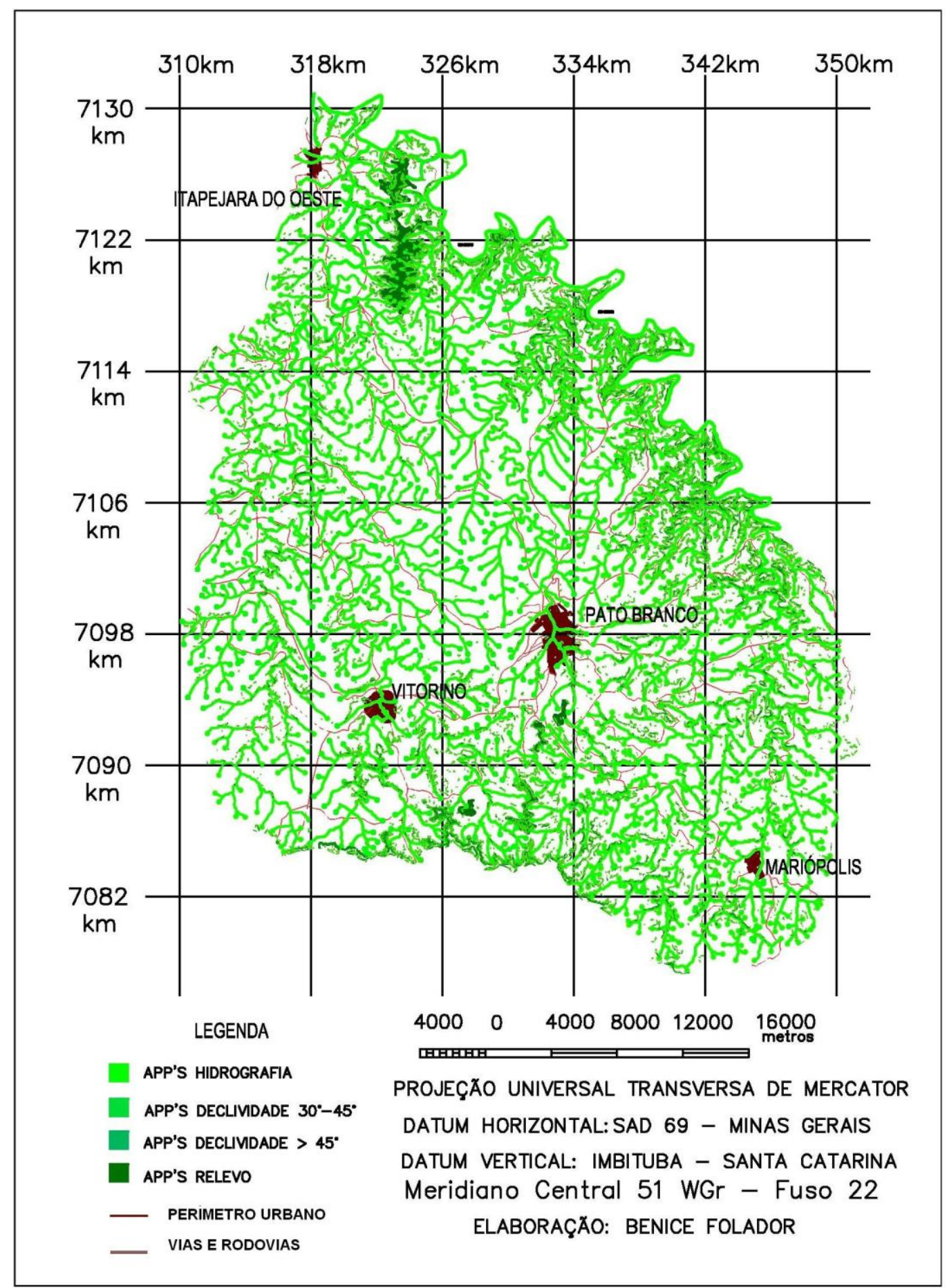

Figura 6 - Mapa Geral das Áreas de Preservação Permanente no Setor Centro Leste do Planalto de Francisco Beltrão.

Nesta análise considerou-se a declividade de $30^{\circ}$ a $45^{\circ}$, com $6 \%$ de cobertura, pelas restrições que estas representam a algumas legislações e critérios ambientais de preservação já abordados anteriormente. Mas considerando-se o que restringe o CFB, apenas $14 \%$ da área de estudo é considerada APP. 


\begin{tabular}{|c|c|c|}
\hline Classes APP & Áreas (ha) & Áreas em \% \\
\hline Hidrografia & $15.218,93$ & 11 \\
\hline Declividade $30^{\circ}-45^{\circ}$ & $7.950,85$ & 6 \\
\hline APP Declividade + de $45^{\circ}$ & $2.190,23$ & 2 \\
\hline Morro & $1.155,59$ & 1 \\
\hline TOTAL & $26.515,60$ & 20 \\
\hline
\end{tabular}

Quadro 2 - APP Setor Centro Leste do Planalto de Francisco Beltrão segundo os critérios de hidrografia e relevo.

Há de se considerar que alguns setores, que configuram APP de declividade, também se encontram em APP relacionadas à variável hidrografia.

\subsection{Uso do solo e APP no setor centro-leste do Planalto de Francisco Beltrão}

Para identificar e quantificar as APP que não estão sendo preservadas, indicando conflito com o uso do solo, primeiramente identificou-se as diferentes classes de uso do solo predominantes na área de estudo. Posteriormente, cruzou-se o mapa de uso do solo com o de APP geral da área, o que permitiu identificar os setores com conflito de uso do solo, a partir da legislação ambiental vigente.

\subsubsection{Classes de uso do solo}

Para cumprir com o objetivo deste trabalho, que se resume em identificar e quantificar áreas de preservação permanente que não estão sendo preservadas, apresentando conflito com uso do solo, identificou-se várias classes de uso do solo (Figura 7), que receberam nome associado ao indicador respectivo como lavoura colhida, floresta, área urbana, lavoura em desenvolvimento e solo exposto (Quadro 3).

Após a elaboração do mapa de uso do solo, as diferentes classes podem ser avaliadas, determinando-se suas respectivas áreas de cobertura. 


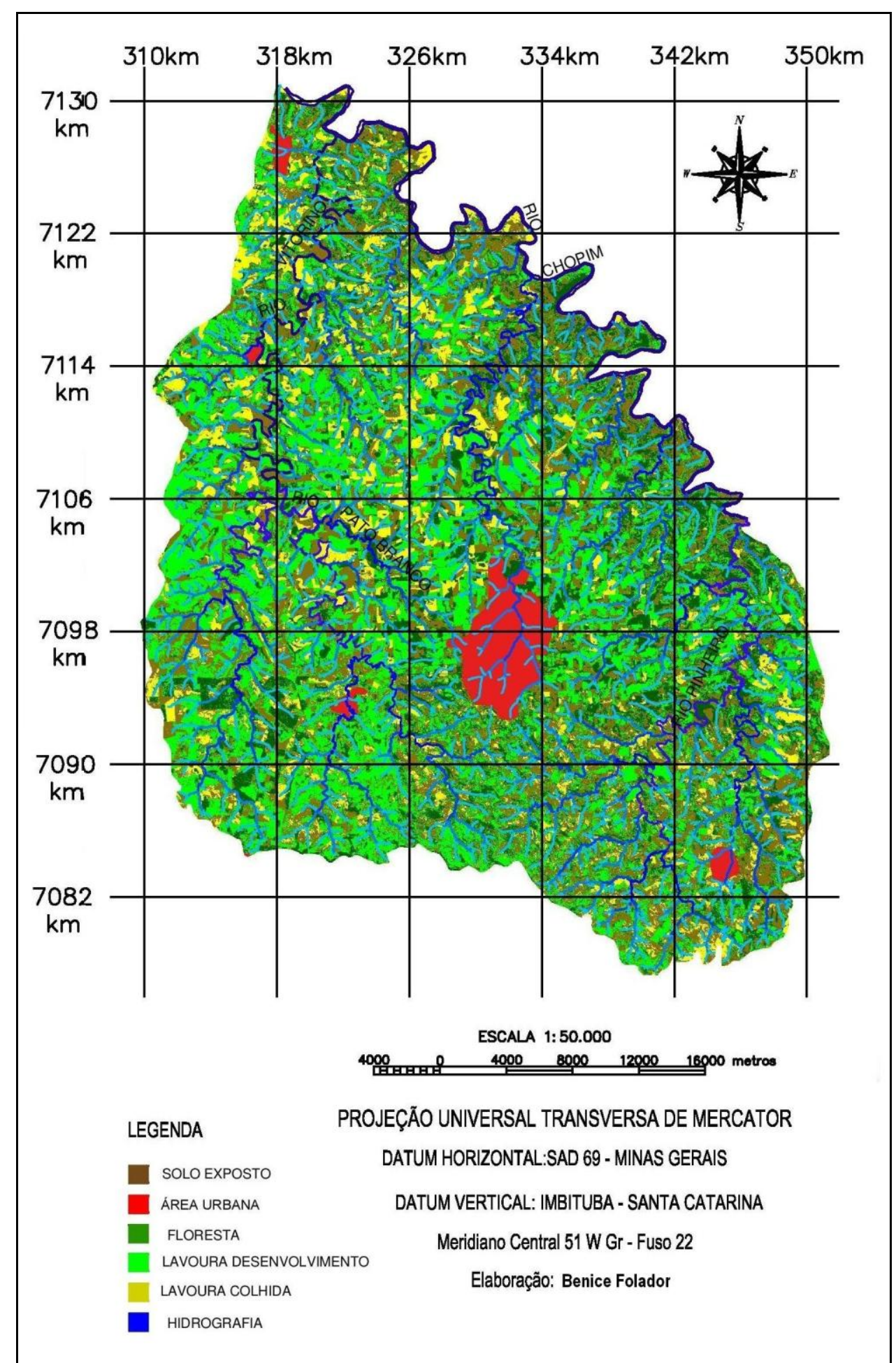

Figura 7 - Mapa de Uso do Solo do Setor Centro Leste do Planalto de Francisco Beltrão.

O uso e ocupação do solo estão diretamente ligados às feições geomorfológicas, tipos de solo, e possibilidades de exploração econômica. O Setor Centro Leste do Planalto de Francisco Beltrão, tem como principal indicador econômico, alta produção agrícola. Isto se confirma pelas classes lavoura colhida e 
lavoura em desenvolvimento dos tipos plantio direto e recém colhida. A classe solo exposto composta por lavoura nova, com resíduos da cultura anterior e possíveis pastagens, totaliza aproximadamente $70 \%$ da área de estudo, onde o uso é caracterizado como áreas agrícolas, em grande parte representada por cultura de grãos, sendo esta região, projeção nacional como maior produtor de grãos como milho, soja e feijão.

\begin{tabular}{|c|c|c|}
\hline Classes Uso do Solo & Áreas em ha (hectare) & Áreas em \% \\
\hline Lavoura Colhida & 12795,26 & 9,20 \\
\hline Floresta & 35363,91 & 25,43 \\
\hline Área Urbana & 4247,97 & 3,05 \\
\hline Lavoura Desenvolvimento & 44338,22 & 31,89 \\
\hline Solo Exposto & 42316,46 & 30,43 \\
\hline TOTAL & 139061,81 & 100,00 \\
\hline
\end{tabular}

Quadro 3 - Uso do Solo no Setor Centro Leste do Planalto de Francisco Beltrão.

Ao norte da área de estudo, onde há maior densidade hidrográfica, se concentra em maior quantidade e maior dimensão as manchas verdes claras e amarelas, respectivas ao uso de lavouras (Figura 7). Neste setor estão as grandes áreas de culturas produtivas, ao contrário do Sudeste onde se concentram as pequenas.

As áreas de agricultura estão concentradas de forma homogênea por toda área de estudo, porém, verifica-se várias áreas de cultura de menor proporção na porção Sul da área de estudo (Figura 7).

O percentual da categoria floresta $(25,43 \%)$ que representa $35.363,91$ ha da área de estudo está no limiar na exigência do Código Florestal que exige, para a região, um mínimo de $20 \%$ de cada propriedade como área de Reserva Legal. Considerando as APP em relação à variável hidrografia, estas representam $11 \%$ da área de estudo com área de 15.218,93 ha.

Nas porções onde a declividade das vertentes é mais acentuada, das médias altitudes até às várzeas, em algumas regiões foi mantida a cobertura vegetal do tipo floresta, principalmente no rio Chopim. A presença de pequenos trechos 
longitudinais de mata ciliar está relacionada ao fato de proprietários rurais terem cumprido o Código Florestal.

Algumas áreas de florestas ocorrem isoladamente e fragmentadas em alta declividade, não propiciando à prática da agricultura (Figura 7).

\subsubsection{Uso do solo versus APP geral}

Para quantificar as áreas de conflito de uso do solo nas APP da área de estudo foram cruzados os mapas das APP com o mapa de uso do solo. Desta forma, foi possível identificar o uso do solo em relação às restrições previstas no CFB e Resoluções do CONAMA. De maneira geral, as classes de uso do solo mapeadas estão parcialmente situadas em áreas legalmente protegidas. No quadro 4 encontram-se os valores das classes de uso do solo nas categorias das APP estudadas.

\begin{tabular}{|c|c|c|}
\hline Classes de Uso do Solo nas APP & Área (ha) & Áreas em \% \\
\hline Lavoura Colhida & 906,32 & 3,59 \\
\hline Floresta & 12128,50 & 48,07 \\
\hline Área Urbana & 419,15 & 1,66 \\
\hline Lavoura em Desenvolvimento & 5573,37 & 22,09 \\
\hline Solo Exposto & 6204,86 & 24,59 \\
\hline TOTAL & 25232,19 & 100,00 \\
\hline
\end{tabular}

Quadro 4 - Uso do solo nas APP

As classes de agricultura, pastagens, lavoura colhida, lavoura em desenvolvimento e solo exposto ocupam 12684,55ha dos 25232,19 ha das APP, equivalente a $50 \%$ das áreas que por força de Lei deveriam ser protegidas. Outros quase $48,07 \%$ estão de acordo com o uso, foram classificados como florestas contemplando matas ciliares, e demonstram estar sendo preservadas. O meio urbano se insere em 1,66 \% das APP. 
Analisando-se o percentual de uso de floresta nas APP, conclui-se que aproximadamente $50 \%$ das áreas estão sendo preservadas. O que é preocupante, considerando que a cobertura florestal total da área de estudo equivale a $25 \%$ e está localizada em áreas inférteis ou de difícil acesso. Áreas de matas ciliares não está sendo preservada.

Para quantificar o uso do solo de forma isolada em cada classe de APP, foi realizado o cruzamento de informações das classes de uso do solo com cada classe de APP. O quadro 5 apresenta a relação do uso do solo nas áreas destinadas às APP relacionadas à variável hidrografia, as quais possuem o maior percentual de ocupação na área de estudo. Observa-se que quase 50\% destas APP estão ocupadas por práticas agrícolas ou de pastagens. Isso evidencia de um lado a aptidão agropecuária da região e, de outro, o não cumprimento da legislação ambiental.

\begin{tabular}{|c|c|c|}
\hline $\begin{array}{c}\text { Classes Uso do Solo } \\
\text { (APP Hidrografia) }\end{array}$ & $\begin{array}{c}\text { Área em ha } \\
\text { (hectare) }\end{array}$ & Áreas em \% \\
\hline Lavoura Colhida & 660,10 & 4,34 \\
\hline Floresta & 7801,60 & 51,26 \\
\hline Área Urbana & 332,00 & 2,19 \\
\hline Lavoura em Desenvolvimento & 3396,01 & 22,31 \\
\hline Solo Exposto & 3029,22 & 19,90 \\
\hline TOTAL & 15218,93 & 100,00 \\
\hline
\end{tabular}

Quadro 5 - Conflito de Uso dos Solos nas APP de Hidrografia na Área de Estudo.

No quadro 6 observa-se o uso do solo nas áreas com inclinação entre $30^{\circ} \mathrm{e}$ 45ㅜ, com relevo fortemente ondulado, próximos aos fundos de vales, e em alguns casos se sobrepondo as APP de mata ciliar, as áreas de ainda fácil acesso, onde os agricultores avançam são tomadas por 32,93 \% da classe de solo exposto, podendo ser lavoura nova ou preparo do solo para culturas permanentes ou temporárias.

Em relação aos outros percentuais de lavoura colhida e lavoura em desenvolvimento, percebe-se quase a metade da classe tomada por práticas agrícolas. 


\begin{tabular}{|c|c|c|}
\hline $\begin{array}{c}\text { Classes de Uso do Solo } \\
\text { (APP Declive 30-45) }\end{array}$ & $\begin{array}{c}\text { Área em ha } \\
\text { (hectare) }\end{array}$ & Áreas em \% \\
\hline Lavoura Colhida & 132,76 & 1,69 \\
\hline Floresta & 3418,68 & 43,40 \\
\hline Area Urbana & 81,16 & 0,10 \\
\hline Lavoura em Desenvolvimento & 1725,24 & 21,90 \\
\hline Solo Exposto & 2593,02 & 32,92 \\
\hline TOTAL & 7950,85 & 100,00 \\
\hline
\end{tabular}

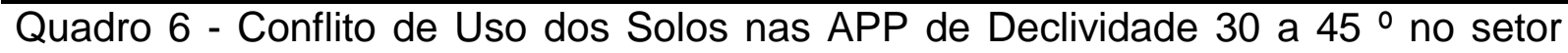
Centro Leste do Planalto de Francisco Beltrão.

Em relação às exigências do Código Florestal no que tange as declividades

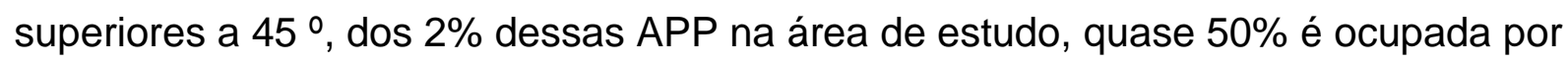
práticas agrícolas (Quadro 7).

Isto demonstra o quanto o monitoramento e a aplicação da legislação ambiental é frágil aos conflitos de uso do solo em relação às APP. Inclinações acima de $45^{\circ}$ possuem formação montanhosa, de difícil acesso. Se estas áreas não forem preservadas dificilmente se garantirá o percentual de $20 \%$ que devem ser destinados às Reservas Legais, sem contar com 0 desequilíbrio ambiental promovido.

\begin{tabular}{|c|c|c|}
\hline $\begin{array}{c}\text { Classes de Uso do Solo } \\
\text { (APP Declive 45-100) }\end{array}$ & $\begin{array}{c}\text { Área em ha } \\
\text { (hectare) }\end{array}$ & Áreas em \% \\
\hline Lavoura Colhida & 13,88 & 0,63 \\
\hline Floresta & 1200,92 & 54,83 \\
\hline Area Urbana & 11,46 & 0,52 \\
\hline Lavoura em Desenvolvimento & 441,92 & 20,18 \\
\hline Solo Exposto & 522,06 & 23,84 \\
\hline TOTAL & 2190,23 & 100,00 \\
\hline
\end{tabular}

Quadro 7 - Conflito de Uso dos Solos nas APP de Declividade superiores a 45 graus, setor Centro Leste do Planalto de Francisco Beltrão.

Considerando as elevações do tipo morro (Quadro 8), apenas 75\% possuem como uso APP. Em uma área que ocupa 1155, 59ha da área de estudo, equivalente a $1 \%$, deste aproximadamente $75 \%$ é destinado a agricultura. 


\begin{tabular}{|c|c|c|}
\hline $\begin{array}{c}\text { Classes de Uso do Solo } \\
\text { (APP Morros) }\end{array}$ & $\begin{array}{c}\text { Área em ha } \\
\text { (hectare) }\end{array}$ & Áreas em \% \\
\hline Lavoura Colhida & 253,34 & 21,92 \\
\hline Floresta & 288,86 & 25,00 \\
\hline Área Urbana & 0,00 & 0,00 \\
\hline Lavoura em Desenvolvimento & 267,09 & 23,11 \\
\hline Solo Exposto & 346,30 & 29,97 \\
\hline TOTAL & 1155,59 & 100,00 \\
\hline
\end{tabular}

Quadro 1 - Conflito de Uso dos Solos nas APP de Morro no setor Centro Leste do Planalto de Francisco Beltrão.

\subsection{As áreas de conflitos entre APP e classes de uso do solo}

Após a elaboração do mapa de uso dos solos, as diferentes classes foram cruzadas com as APP, obtendo-se, assim, as áreas que estariam sendo conservadas pela legislação ambiental vigente, bem como os setores de conflito de uso do solo (Figura 8).

O cruzamento de informações de uso de solo e APP indica o predomínio das áreas de conflito de uso em relação àquelas conservadas.

Observa-se que a concentração de áreas de conflito residem ao longo da margem do rio Chopim, bem como de seus afluentes nas proximidades da confluência. Principalmente nos setores de médio e baixo curso do rio Ligeiro, e nos afluentes menores do rio Chopim, distribuídos entre o rio Ligeiro e Pinheiro (Figura 8).

Apesar de, visualmente, as áreas de conflito relacionadas às nascentes de canais não demonstrarem manchas expressivas, é preciso considerar o grande número de pontos distribuídos aleatoriamente em toda a área de estudo. Isso demonstra que boa parte das APP relacionadas à nascentes, junto às margens dos rios não estão sendo preservadas.

No limite sul da área de estudo nota-se manchas de conflito que se sobressaem, principalmente ao longo de divisor de águas regional (bacias Chopim e Chapecó - Uruguai), bem como em divisores locais entre as sub-bacias dos rios Pinheiro a leste e Pato Branco a oeste (Figura 8). 
Destaca-se, ainda, que a totalidade da mancha de APP demarcada pela elevação de relevo (topo de morro) mostra-se sendo utilizada para uso de pastagens e culturas (Figura 8).

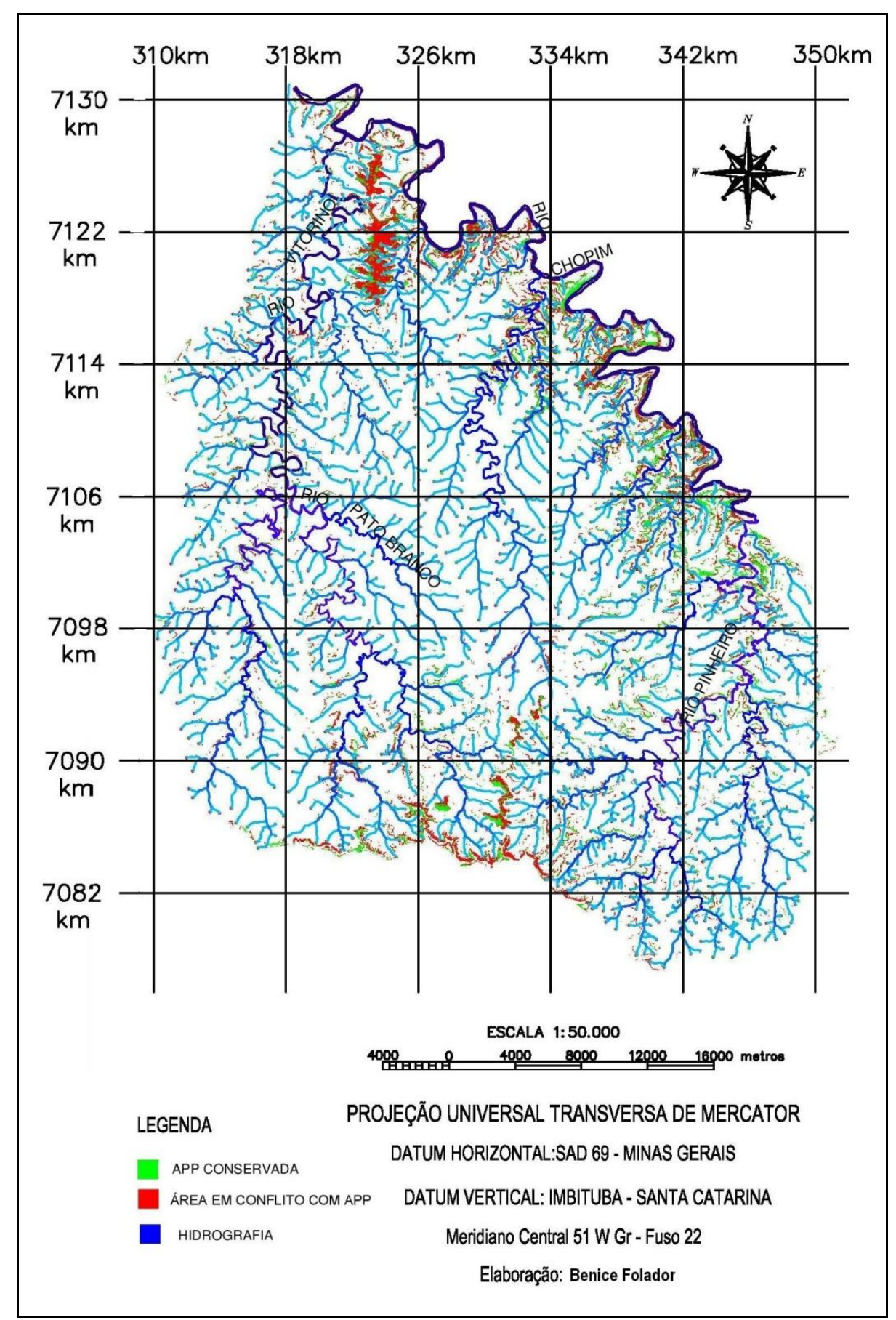

Figura 8 - Mapa de Uso do Solo em Conflito com APP - Setor Centro Leste do Planalto de Francisco Beltrão 
Além da APP de elevação do relevo, ainda é preciso considerar as inúmeras áreas de APP relacionadas a cabeceiras de drenagem (nascentes) que se encontram no topo desta superfície de morro.

Posteriormente, com o objetivo de ressaltar os setores em que se identificam conflitos de uso do solo com APP, realizou-se a reclassificação do uso do solo em duas categorias: adequado e inadequado. Gerou-se, assim, mapa de conflito de uso do solo para a área estudada (Figura 9). 


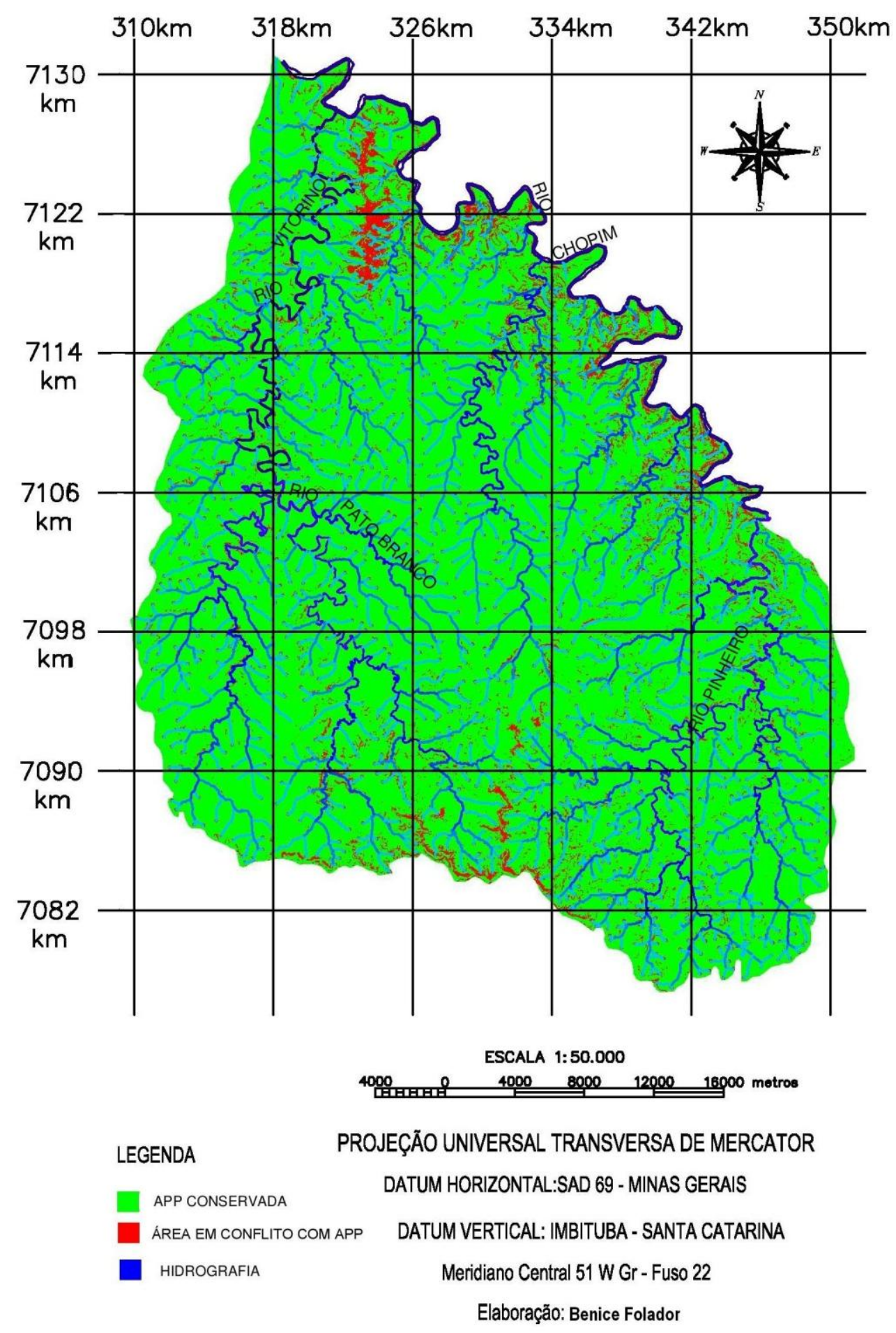

Figura 9- Mapa de Conflito de Uso do Solo no setor Centro Leste do Planalto de Francisco Beltrão.

As APP ocupadas com floresta foram consideradas uso adequado do solo e perfazem total de 13.103,70ha (Figura 9). Aquelas áreas que foram indicadas pelas variáveis relevo e hidrografia como de APP e que a análise de uso do solo mostrou ocupação, seja com lavoura em desenvolvimento, lavoura colhida, área urbana ou 
solo exposto, foram consideradas uso inadequado do solo. Essas representam área de 12.128,50ha no setor centro-leste do Planalto de Francisco Beltrão.

\section{CONCLUSÃO}

A análise das variáveis do meio físico, relevo e hidrografia, associado à legislação ambiental em vigor, permitiu definir as áreas consideradas como de APP pelo Código Florestal Brasileiro no setor centro-leste do Planalto de Francisco Beltrão. O cruzamento das APP com o uso do solo mostrou os locais de conflito de uso que ocorrem na área.

As altitudes, na área de estudo, se distribuem entre $480 \mathrm{~m}$ e $1080 \mathrm{~m}$. A distribuição das classes hipsométricas permitiu destacar três agrupamentos de intervalos predominantes: de 480 a $660 \mathrm{~m}$; 661 a 780 ; e de 781 a $1080 \mathrm{~m}$, respectivamente correspondendo a $26,2 \%, 42,8 \%$ e $31 \%$ da área de estudo. Pelo que estabelece o CFB não há, a priori, áreas consideradas de preservação permanente de acordo com a hipsometria.

Este código estabelece como APP altitudes acima de $1800 \mathrm{~m}$. No entanto, a análise da distribuição das curvas de nível, que representam as elevações do terreno existentes na área, possibilitou individualizar setores de APP relacionadas ao relevo. As APP relevo são restritas e correspondem a manchas que representam pequenos morros isolados, configurando-se como divisores de águas entre afluentes dos canais das sub-bacias.

Predominam no setor centro-leste do Planalto de Francisco Beltrão

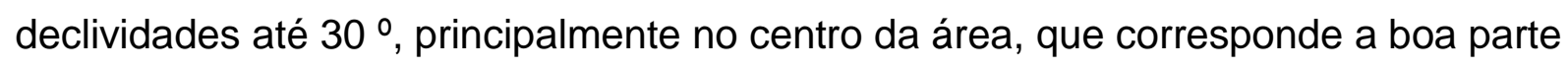
do município de Pato Branco. Declividades maiores de $30^{\circ}$ ocorrem praticamente ao longo de toda a margem esquerda do rio Chopim e no extremo sul da área, no divisor regional de águas entre os estados do Paraná e Santa Catarina. Além desses setores, destaca-se a concentração de APP em relação à declividade ao longo de toda a sub-bacia do Rio Pinheiro, especialmente nos divisores de água dos canais de $1^{\underline{a}}$ e $2^{\underline{a}}$ ordens de grandeza.

Pela legislação vigente no CFB, que considera declividades igual ou superior a $45^{\circ}$ - relevo montanhoso, como APP, apenas $2 \%$ de toda área de estudo seriam destinados à preservação. Já se for considerado o parâmetro de declividades 
superiores a 30ำ - relevo fortemente ondulado, como de APP, $19 \%$ da área total no setor centro-leste do Planalto de Francisco Beltrão seriam protegidas.

A área de estudo é drenada por canais de $1^{\underline{a}}$ a $6^{\underline{a}}$ ordens hierárquicas, sendo que somente o Rio Vitorino, a partir da confluência com o rio Pato Branco, apresenta hierarquia de canal de $6^{\underline{a}}$ ordem.

As APP relacionadas à hidrografia distribuem-se de modo uniforme por toda a área de estudo, constituindo densidade alta de manchas, relacionadas tanto aos setores das cabeceiras dos segmentos de canais de 1aㅡ ordem hierárquica, quanto das margens dos rios. Nesses últimos, quanto maior a largura dos canais de drenagem, tanto maior a extensão de preservação nas margens. As manchas de APP relacionadas às cabaceiras de canais predominam no setor correspondente ao município de Mariópolis, próximo a divisa dos Estados de Santa Catarina e Paraná.

Da área total (139.061,81ha) do setor centro leste do Planalto de Francisco Beltrão, 26.515,60ha são consideradas áreas sensíveis ao meio ambiente. De acordo com as categorias de APP analisadas (elevações do relevo, declividade acima de 30ㅜㅡ, hidrografia), e com o que define o Código Florestal como APP, 19\% da área de estudo são protegidas pela legislação.

Dos tipos de APP existentes na área estudada, a preservação ao longo dos cursos d'água responde pela maior extensão das áreas protegidas (15.218,93ha). As menores participações entre as APP correspondem às encostas com declividade superior a 45ำ (2.190,23ha), e as APP de categoria Morro (1.155,59ha).

Identificou-se cinco classes de uso do solo no setor centro leste do Planalto de Francisco Beltrão: lavoura colhida, floresta, área urbana, lavoura em desenvolvimento e solo exposto. A escolha das classes foi consonante com a resolução espacial das imagens SPOT-5. Dos 139.061,81ha de área total, a classe lavoura colhida representa $9,20 \%$, a floresta $25,43 \%$, área urbana 3,05\%, lavoura em desenvolvimento $31,89 \%$ e solo exposto $30,43 \%$. Observa-se que $71,51 \%$ da área total representam uso agrícola.

As áreas de conflito de uso concentram-se ao longo da margem do rio Chopim, bem como de seus afluentes nas proximidades da confluência. Aquelas relacionadas às nascentes de canais, apesar de visualmente não demonstrarem manchas expressivas, se constituem em grande número distribuídas aleatoriamente em toda a área de estudo. Isso demonstra que boa parte das APP relacionadas às 
nascentes, no setor Centro-Leste do Planalto de Francisco Beltrão, não estão sendo preservadas. No limite Sul da área de estudo aparecem manchas de conflito, principalmente ao longo de divisor de águas regional, bem como em divisores locais entre as sub-bacias dos rios Pinheiro a leste e Pato Branco a oeste.

As APP ocupadas com florestas foram consideradas uso adequado do solo e perfazem total de 13.103,70ha. Aquelas áreas que foram indicadas pelas variáveis relevo e hidrografia como de APP e que a análise de uso do solo mostrou ocupação, seja com lavoura em desenvolvimento, lavoura colhida, área urbana ou solo exposto, foram consideradas uso inadequado do solo. Essas representam área de 12.128,50ha no setor centro-leste do Planalto de Francisco Beltrão.

\section{BIBLIOGRAFIA}

ANTUNES, Paulo B. Direito Ambiental. Rio de Janeiro. Lumen Juris, 2008.

AB'SÁBER, Aziz Nacib. Do Código Florestal para o Código da Biodiversidades. São Paulo, 2010.

BHERING, S. B; SANTOS, H. G. (ED). Mapa de Solos do Estado do Paraná: Legenda Atualizada. Rio de Janeiro: Embrapa Solos, 2008.

KOEPPEN, W. Climatologia. Mexico, Fundo de Cultura Economica, 1948.

EMBRAPA, Centro Nacional de Pesquisa de Solo (Rio de Janeiro, RJ). Sistema Brasileiro de Classificação de Solos. Rio de Janeiro, 1999, 412p.

FODOR, R. V.; MCKEE, E. M.; ROISENBERG, A. Agedistribution of Serra Geral (Paraná) flood basalts,southern Brazil. Journal of South American Earth Sciences, Oxford, v. 2, p. 343-349, 1989.

Lei n. 4.771 de 15 de setembro de 1965. Código Florestal Brasileiro (incluído pela Medida Provisória no 2.166-67, de 2001, p.1). Brasília, DF, 15 de setembro de 1965. MAACK, R. Geografia física do estado do Paraná. Curitiba: J. Olympio, 1981

MENDONÇA, Francisco. Diagnóstico e Análise Ambiental de Microbacia Hidrográfica:Proposição Metodológica na Perspectiva do Zoneamento, Planejamento e Gestão Ambiental. RA'E GA:Espaço Geográfico em Análise. Departamento deGeografia. Editora da UFPR Curitiba, n.03, ano III, 1999.

MENDONÇA. F. O Espaço Geográfico Em Análise - Diagnóstico E Análise Ambiental de Microbacia Hidrográfica: Proposição Metodológica na Perspectiva do Zoneamento, Planejamento e Gestão Ambiental - Departamento de Geografia n. 03, ano III. Curitiba, 1999. 
METZGER, J.P. Fundamentos Científicos Do Código Florestal. Disponível:< http://umcodigopelavida.wordpress.com/2010/08/17/jean-paul-metzger fundamentoscientificos-do-codigo-florestal/>. Acesso em: 04 março 2011.

NARDY, A.J.R.; PICCIRILLO, E. M.; COMIN-CHIARAMONTI, P.; MELFI, A.J.; BELLIENI, G.; OLIVEIRA, M.A.F. Caracterização Litoquímica e Aspectos Petrológicos de Rochas Vulcânicas Da Formação Serra Geral: Região Centro Sul do Estado do Paraná. Geociências. São Paulo, 1998.

NARDY A. J. R., OLIVEIRA M. A. F., BETANCOURT R. H. S.,VERDUGOS D. R., MACHADO F. B. Geologia e Estratigrafia da Formação Serra Geral. Geociências. São Paulo. UNESP. V. 12. N. 1/25, p. 15-32. 2002.

NEVES et. al.. Análise das Relações entre Solos, Relevo e a Legislação Ambiental para a Delimitação das Áreas de Preservação Permanente: 0 Exemplo da Alta Bacia do Ribeirão João Leite, Estado de Goiás. Revista Brasileira de Geomorfologia. Uberlândia, v. 10, n. 1, p. 3-21, 2009.

NOGUEIRA, R.E. Cartografia, Comunicação e Visualização de Dados Espaciais. $2^{a}$ ed. Florianópolis: Editora da UFSC, 2008.

PAISANI, J.C.; GEREMIA, F. Evolução de encostas no planalto basáltico com base na análise de depósitos de colúvio - Médio Vale do rio Marrecas, SW do Paraná - Universidade Estadual do Oeste do Paraná, Francisco Beltrão.

PAISANI, J; PONTELLI, M.E.; ANDRES, J.; PASA, V.;MARINHO, F.R. Características Geológicas da Formação Serra Geral na área Drenada pelo Rio Marrecas (SW PR): Fundamentos para a Análise Geomorfológica. Geografia, V.17, n.2, p. 49-65, 2008.

PAISANI, J.C.; PONTELLI. M. E.; FORTES, J.A.E. Superfícies Aplainadas Em Zona Morfoclimática Subtropical Húmida No Planalto De Basáltico Da Bacia Do Paraná (Sw Paraná/Nw Santa Catarina): Primeira Aproximação. Geociências. v. 27, n.4 p. 541-553, UNESP. São Paulo, 2008.

Resolução CONAMA n. 371, de 20 de março de 2006. Dispõe sobre parâmetros, definições e limites de Áreas de Preservação Permanente. Diário Oficial da República Federativa do Brasil, Brasília, DF, n. 90, de 13 de maio de 2002, seção 1, p.68. Disponível em:< http://www.mma.gov.br/pot/conama/res/res02/res371.html>. Acesso em: 24 março 2009>.

SCHNEIDER, R. L.; MÜHLMANN, H.; TOMMASI, E.; MEDEIROS, R. A.; DAEMON, R. F.; NOGUEIRA, A. A. Revisão estratigráfica da Bacia do Paraná. In: CONGRESSO BRASILEIRO DE GEOLOGIA, 28., 1974, Porto Alegre. Paulo: Sociedade Brasileira de Geologia, 1974. v. 1, p. 41-65.

VOLKMER, S.; RIBEIRO, E.M. Análise geomorfológica preliminar do planalto de Palmas na região homônima. In: SIMPÓSIO NACIONAL DE GEOMORFOLOGIA, 
5, E ENCONTRO SUL-AMERICANO DE GEOMORFOLOGIA, 1, 2004, Santa Maria. Anais... Santa Maria: UFSM, 2004.

VOLKMER, Susana; FORTES, Edison. Análise Preliminar da Geomorfologia dos Terrenos Vulcânicos da Região Oeste do Estado do Paraná. In: SIMPÓSIO BRASILEIRO DE GEOGRAFIA FÍSICA APLICADA, X, Brasil, 2003.

VOLKMER, Susana; MONTEIRO Elaine R. Análise Geomorfológica Preliminar do Planalto de Palmas na Região Homônima. In: SIMPÓSIO NACIONAL DE GEOMORFOLOGIA/ ENCONTRO SUL AMERICANO DE GEOMORFOLOGIA, V, 2004, Santa Maria.

(Recebido em 07.02.2013. Aceito em 10.06.2013) 